\title{
Fractionated stereotactic conformal radiotherapy for large benign skull base meningiomas
}

\author{
Giuseppe Minniti ${ }^{1,3 *}$, Enrico Clarke ${ }^{1}$, Luigi Cavallo², Mattia Falchetto Osti ${ }^{1}$ Vincenzo Esposito ${ }^{3}$, Gianpaolo Cantore ${ }^{3}$, \\ Paolo Cappabianca ${ }^{2}$ and Riccardo Maurizi Enrici ${ }^{1}$
}

\begin{abstract}
Purpose: to assess the safety and efficacy of fractionated stereotactic radiotherapy (FSRT) for large skull base meningiomas.

Methods and Materials: Fifty-two patients with large skull base meningiomas aged 34-74 years (median age 56 years) were treated with FSRT between June 2004 and August 2009. All patients received FSRT for residual or progressive meningiomas more than 4 centimeters in greatest dimension. The median GTV was $35.4 \mathrm{~cm}^{3}$ (range 24.1-94.9 $\mathrm{cm}^{3}$ ), and the median PTV was $47.6 \mathrm{~cm}^{3}$ (range 33.5-142.7 $\mathrm{cm}^{3}$ ). Treatment volumes were achieved with 5-8 noncoplanar beams shaped using a micromultileaf collimator (MLC). Treatment was delivered in 30 daily fractions over 6 weeks to a total dose of 50 Gy using $6 \mathrm{MV}$ photons. Outcome was assessed prospectively.

Results: At a median follow-up of 42 months (range 9-72 months) the 3-year and 5-year progression-free survival (PFS) rates were $96 \%$ and $93 \%$, respectively, and survival was 100\%. Three patients required further debulking surgery for progressive disease. Hypopituitarism was the most commonly reported late complication, with a new hormone pituitary deficit occurring in $10(19 \%)$ of patients. Clinically significant late neurological toxicity was observed in 3 (5.5\%) patients consisting of worsening of pre-existing cranial deficits.

Conclusion: FSRT as a high-precision technique of localized RT is suitable for the treatment of large skull base meningiomas. The local control is comparable to that reported following conventional external beam RT. Longer follow-up is required to assess long term efficacy and toxicity, particularly in terms of potential reduction of treatment-related late toxicity.
\end{abstract}

\section{Introduction}

The optimal management of large benign meningiomas of the skull base is challenging. Surgery remains the standard treatment and following apparently complete removal the reported control rates are in the region of $95 \%$ at 5 years and $90 \%$ at 10 years [1-14]. However, a significant subset of meningiomas, especially large tumors involving the cavernous sinus, the petroclival region, and the brainstem cannot be completely resected for the risk of significant morbidity [1,3-6,9]. In such patients incomplete removal of tumor with preservation of the involved cranial nerves may result in improved neurological function and temporary local control,

\footnotetext{
* Correspondence: giuseppe.minniti@ospedalesantandrea.it 'Department of Radiation Oncology, Sant' Andrea Hospital, Università degli Studi di Roma "La Sapienza", Rome, Italy

Full list of author information is available at the end of the article
}

although progression on long-term follow-up is reported in up to $80 \%$ of patients $[2,8,13]$.

Local control following partial resection of benign meningiomas and at the time of recurrence can be improved with conventional fractionated external beam radiotherapy (RT), with a reported 10-year progressionfree survival in the region of $75-90 \%$ [15-17]. More recently, stereotactic radiation techniques in form of stereotactic radiosurgery (SRS) and fractionated stereotactic radiotherapy (FSRT) have been developed as accurate techniques that can deliver more localized irradiation with a steeper dose gradient between the tumor and the surrounding normal tissue, and consequently reducing the volume of normal brain irradiated to high radiation doses. Both techniques have been reported as an effective treatment in several benign skull base tumors including pituitary adenomas $[18,19]$, 
acoustic neuromas [20,21], craniopharyngiomas [22,23] and meningiomas [24].

Although in many centers SRS is the preferred treatment option for patients with small to moderate recurrent or enlarging skull base meningiomas, fractionated RT is often performed for larger tumors close to critical structures because of the radiobiological advantage of dose fractionation in reducing the risk of post-radiation long-term complications. In this study, we report the experience with FSRT at our center for patients with large residual or progressive skull base meningiomas.

\section{Patients and Methods}

Between June 2004 and August 2009, fifty-two patients with benign skull base meningiomas more than 4 centimeters in greatest dimension were treated with FSRT. Characteristics of patients are shown in Table 1. There were 17 males and 35 females. Median age was 56 years, ranging from 34 to 74 years. All patients had a KPS $\geq$ 60. Eighteen received FSRT following surgery for a macroscopic tumor remnant and the other 34 patients had FSRT at tumor regrowth. Twenty-one patients had more than one surgical procedure. Histology confirmed the presence of a benign meningioma in all cases.

\begin{tabular}{|c|c|}
\hline Sex & $17 \mathrm{M} \backslash 35 \mathrm{~F}$ \\
\hline Median age (range) & 56 yrs (34-74) \\
\hline \multicolumn{2}{|l|}{ KPS } \\
\hline \multicolumn{2}{|l|}{$70-80$} \\
\hline \multicolumn{2}{|l|}{$90-100$} \\
\hline Neurological deficits & 43 \\
\hline \multicolumn{2}{|l|}{ Number of surgeries } \\
\hline 1 & 31 \\
\hline 2 & 16 \\
\hline 3 & 5 \\
\hline \multicolumn{2}{|l|}{ Pituitary function } \\
\hline normal & 45 \\
\hline hypopituitarism & 7 \\
\hline \multicolumn{2}{|l|}{ Tumor site } \\
\hline cavernous sinus & 38 \\
\hline petroclival & 6 \\
\hline Sphenoid wing & 4 \\
\hline cerebellopontine angle & 5 \\
\hline \multicolumn{2}{|c|}{ Gross tumour volume (GTV) } \\
\hline Median & $35.4 \mathrm{~cm}^{3}$ \\
\hline Range & $24.1-94.9 \mathrm{~cm}^{3}$ \\
\hline \multicolumn{2}{|c|}{ Planning target volume (PTV) } \\
\hline Median & $47.6 \mathrm{~cm}^{3}$ \\
\hline Range & $33.5-142.7 \mathrm{~cm}^{3}$ \\
\hline
\end{tabular}

MRI, magnetic resonance images;
Table 2 Cranial deficits at presentation in $\mathbf{5 2}$ patients with large skull base benign meningiomas

\begin{tabular}{ccc}
\hline Cranial deficits* & Before FSRT & $\begin{array}{c}\text { After FSRT } \\
\text { (median follow-up 34 months) }\end{array}$ \\
\hline II & 22 & $16^{* *}$ \\
II & 10 & 8 \\
IV & 2 & 2 \\
V & 9 & 6 \\
VI & 11 & 8 \\
VII & 5 & 3 \\
VIII & 4 & $6^{* *}$ \\
\hline
\end{tabular}

*14 patients had multiple cranial deficits at presentation.

** One patient with visual field defect and 2 patients with hearing loss had clinical deterioration during the follow-up.

Cranial nerve deficits were present in 43 patients, mainly consisting of visual field defects in 22 and/or impaired ocular motility in 19 (Table 2). Endocrine deficits were present in 7 patients. The median time from resection to FSRT was 39 months. None of patients had received previous radiotherapy.

\section{SCRT technique and dose prescription}

The FSRT technical details and procedure using the BrainLab stereotactic mask fixation system have been previously reported [25]. The gross tumor volume (GTV) was delineated on the basis of the contrastenhancing tumor demonstrated on T1-weighted MRI fused with the simulation CT images. CTV was considered the same as GTV. The planning target volume (PTV) was generated by the geometric expansion of GTV plus $2-3 \mathrm{~mm}$. For the last 18 patients the 3-D margin was reduced to $2 \mathrm{~mm}$. The median GTV was $35.4 \mathrm{~cm}^{3}$ (range 24.1-94.9 $\mathrm{cm}^{3}$ ). The PTV was $47.6 \mathrm{~cm}^{3}$ (range 33.5-142.7 $\mathrm{cm}^{3}$ ). Treatment volumes were achieved with 5-8 noncoplanar beams shaped using a micromultileaf collimator (MLC). Plans were prescribed at the isocentre according to ICRU 50 criteria with PTV covered by the $95 \%$ isodose in 3-D. To assess the accuracy of relocation, the isocentre position was verified with a second CT scan performed just prior to the start of treatment. The tolerance of relocation had to be $<$ $1.5 \mathrm{~mm}$ in any direction. Daily portal images acquired at 0 and $90^{\circ}$ through the isocenter were obtained for each patient during the treatment. All patients were treated on a 6-MV LINAC with a 120 leaf MLC (Varian Clinac $600 \mathrm{DBX})$ and received a dose of 50 Gy in 30 fractions over 6 weeks.

\section{Follow-up and data analysis}

A clinical assessment of neurological status and tolerance to treatment was performed every six months. An MRI scan was performed every 6 months for the first 2 years and thereafter every 12 months. Tumor control 
was defined by the absence of radiological tumor progression. Pituitary function was assessed by complete basal hormonal assessment and dynamic testing, as appropriate, in an endocrine clinic. Vision was assessed by serial ophthalmologic examinations. Tumor control and overall survival were measured from the start of FSRT. Univariate analysis and multivariate Cox proportional hazards regression model were used to test the effect of prognostic factors on tumor control.

\section{Results}

\section{Tumor control and survival}

Fifty-two patients with large benign skull base meningioma were treated with FSRT. At the time of analysis in December 2010, three patients had tumor progression 18, 30 and 42 months after FSRT and required surgery. After a median follow-up of 42 months (range from 12 months to 72 months), the actuarial tumor control was $96 \%$ at 3 years and $93 \%$ at 5 years, and respective survival $100 \%$ (Figure 1). Local control was similar for patients treated with FSRT as a part of their primary treatment or at the time of recurrence. MRI showed on serial imaging no changes in 37 (71\%) and reduction in tumor size in 12 patients (23\%), however without reaching conventional partial response criteria. Univariate analysis showed no significant tumor control between 23 meningiomas larger than $40 \mathrm{~cm}^{3}$ and 29 meningiomas smaller than or equal to $40 \mathrm{~cm}^{3}(P=0.16)$ (Figure 2). Similarly, tumor location, sex, and age were not correlated with tumor control.

\section{Neurological function}

Neurological deficits were present in 43 (82\%) patients. After FSRT 11 (20\%) patients had a clinical improvement of neurological deficits (Table 2). Vision improved

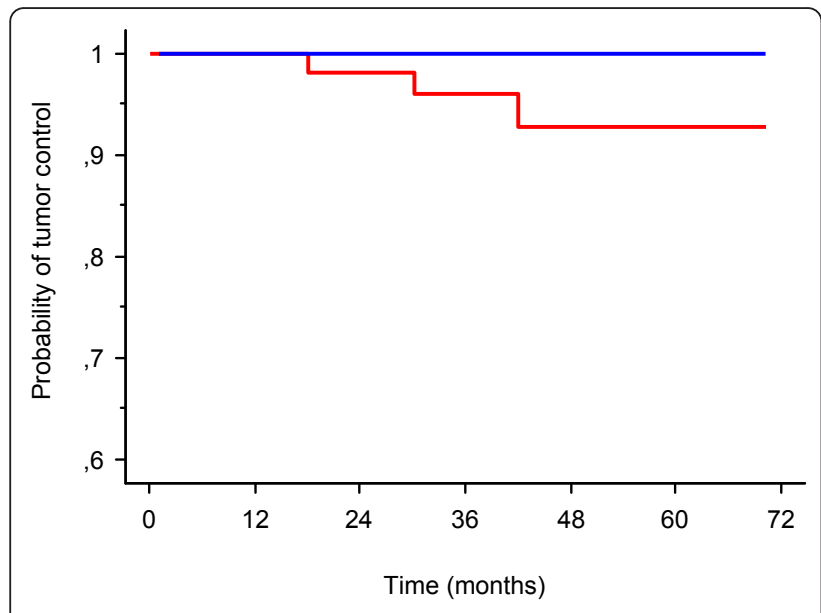

Figure 1 Kaplan-Meier analysis of tumor control (red line) and overall survival (blue line) rates after FSRT of $\mathbf{5 2}$ large benign skull base meningiomas.

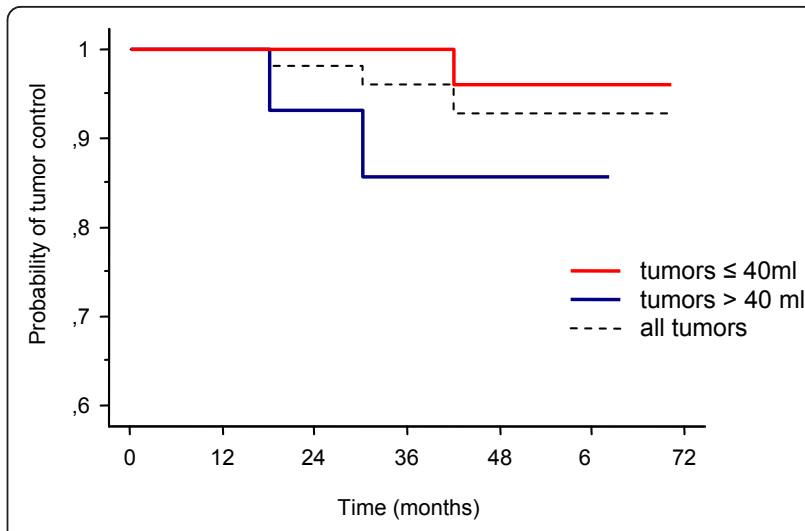

Figure 2 Kaplan-Meier analysis of tumor control in patients with large benign skull base meningiomas treated with fractionated stereotactic radiotherapy (FSRT) according to tumor volume $(\leq 40 \mathrm{ml}$ versus $>40 \mathrm{ml})(p=0.16)$

in 7 patients and cranial nerve function in 5 patients. The optic chiasm was included in the PTV of the majority of patients $(n=36)$ and received the prescribed dose of $50 \mathrm{~Gy}$. Three patients deteriorated without evidence of tumor progression on imaging. One patient had a slight worsening of vision and two progressive hearing loss. Seven patients had a transient mild visual deterioration $(\mathrm{n}=4)$ and a worsening of pre-existing $7^{\text {th }}(\mathrm{n}$ $=1)$ and $5^{\text {th }}(\mathrm{n}=2)$ nerve palsy during or shortly after treatment, with full recovery after a short course of corticosteroids.

\section{Acute and late toxicity}

All patients noted transient localized alopecia at the beam entrance with full subsequent recovery of hair growth. Tiredness occurred in 14 (27\%) patients, lasting for 4-8 weeks after FSRT. Transient headache occurred in 6 patients. One patient had an increase in seizure frequency. A development of new or worsening of preexisting hypopituitarism occurred in 10 (19\%) patients after a median follow-up of 36 months, requiring hormone replacement therapy with gonadal steroids and growth hormone in 7 patients, GH replacement in 2 patients, and thyroxine and hydrocortisone in 4 patients. The pituitary fossa contained residual tumor in 27 patients, and was included in the PTV. New clinically apparent neurocognitive dysfunction (Grade II RTOG memory impairment) was reported in one patient. No radiation necrosis, cerebrovascular accidents and second tumors were reported.

\section{Discussion}

Fifty-two patients with large skull base meningiomas were treated with FSRT between June 2004 and August 2009 at University of Rome "La Sapienza". At a median follow-up of 42 months tumor control rates were $96 \%$ 
and $93 \%$ at 3 and 5 years, with respective survival of $100 \%$. The rate of complications was acceptable, consisting mainly in worsening vision in 2 patients and pituitary hormone deficits in 10 patients. The reported tumor control rate is similar to that shown recently by others following conventional RT [15-17,26-33] or FSRT [34-45](Table 3), however longer follow-ups needed to confirm the excellent results obtained in our series. Of note, in our study we have considered only patients presenting with large benign meningiomas more than 4 centimeters in greatest dimension, with a median volume of $35.4 \mathrm{~cm}^{3}$. Milker-Zabel et al. [39] reported on 317 patients with benign skull base meningiomas of a median volume of $34 \mathrm{~cm}^{3}$ treated with FSRT at University of Heidelberg. At a median follow-up of 5.7 years, 5 -year and 10 -year tumor control rates were $90.5 \%$ and $89 \%$, and respective survival were $95 \%$ and $90 \%$. Hamm et al [42] reported on 183 patients with large skull base meningiomas up to $135 \mathrm{~cm}^{3}$ or close to optical structures treated with FSRT with a median dose of 56 Gy with daily fractions of 1.8-2 Gy. At a median follow-up of 36 months the overall survival and the progressionfree survival rates for 5 years were $92.9 \%$, and $96.9 \%$, respectively. Grade II-III late neurological toxicity occurred in $5.5 \%$ of patients. A similar tumor control has been reported in patients with skull base meningiomas treated with conventional RT, however with an increased risk of recurrence for larger tumors $[15,28,29]$. Connell et al [29] reported a 5-year control of $93 \%$ for 54 patients with skull base meningiomas less than 5 centimeters in greatest dimension and $40 \%$ for tumors more than 5 centimeters, and similar findings have been reported by others [15,28]. Although a clear limitation of the study is represented by the relatively short followup, neverthless our results and data from literature suggest that FSRT is an appropriate treatment option for patients with large recurrent or enlarging skull base meningiomas with a 5-year control similar or even better than conventional $R T$.

The external beam radiation dose for meningioma that represents the best balance of tumor control and a low complication rate has not been defined. Most of published series show no significant difference on tumor control with the use of doses ranging between 50 and $60 \mathrm{~Gy}$, however a dose $<50$ Gy has been associated with higher recurrence rates $[15,27,33]$. The present

Table 3 Summary of main results on published studies on the conformal radiotherapy and FSRT of skull base meningiomas

\begin{tabular}{|c|c|c|c|c|c|c|c|}
\hline authors & $\begin{array}{l}\text { Patients } \\
\text { (n) }\end{array}$ & $\begin{array}{c}\text { Technique } \\
\text { (\%) }\end{array}$ & $\begin{array}{l}\text { Volume } \\
\text { (ml) }\end{array}$ & $\begin{array}{l}\text { Dose } \\
\text { (Gy) }\end{array}$ & $\begin{array}{l}\text { Follow-up } \\
\text { (months) }\end{array}$ & $\begin{array}{c}\text { Local control } \\
(\%)\end{array}$ & $\begin{array}{c}\text { Late toxicity } \\
(\%)\end{array}$ \\
\hline Goldsmith et al., 1994 & 117 & CRT & NA & 54 & 40 & 89 at 5 and 77 at 10 years & 3.6 \\
\hline Maire et al., 1995 & 91 & CRT & NA & 52 & 40 & 94 & 6.5 \\
\hline Peele et al., 1996 & 42 & CRT & NA & 55 & 48 & 100 & 5 \\
\hline Condra et al.,1997 & 28 & CRT & NA & 53.3 & 98 & 87 at 15 years & 24 \\
\hline Connell et al., 1999 & 54 & CRT & NA & 54 & 55 & 76 at 5 years & 19 \\
\hline Maguire et al., 1999 & 26 & CRT & NA & 53 & 41 & 8 at 8 years & 8 \\
\hline Nutting et al., 1999 & 82 & CRT & NA & $55-60$ & 41 & 92 at 5 and 83 at 10 years & 14 \\
\hline Vendrely et al., 1999 & 156 & CRT & NA & 50 & 40 & 79 at 5 years & 11.5 \\
\hline Dufour et al., 2001 & 31 & CRT & NA & 52 & 73 & 93 at 5 and 10 years & 3.2 \\
\hline Pourel et al., 2001 & 28 & CRT & NA & 56 & 30 & 95 at 5 years & 4 \\
\hline Mendenhall et al., 2003 & 101 & CRT & NA & 54 & 64 & 95 at 5,92 at 10 and 15 years & 8 \\
\hline Debus et al., 2001 & 189 & FSRT & 52.5 & 56.8 & 35 & 97.3 & 1.6 \\
\hline Jalali et al., 2002 & $41^{*}$ & FSRT & 17.9 & 55 & 21 & 100 & 12.1 \\
\hline Lo et al., 2002 & $18^{*}$ & FSRT & 8.8 & 54 & 30.5 & 93.3 & 5 \\
\hline Torres et al., 2003 & $77^{*}$ & FSRT & 16.1 & 48.4 & 24 & 97.2 & 5.2 \\
\hline Selch et al., 2004 & 45 & FSRT & 14.5 & 56 & 36 & 100 at 3 years & 0 \\
\hline Milker-Zabel et al., 2005 & $317^{*}$ & FSRT & 33.6 & 57.6 & 67 & 90.5 at 5 and 89 at 10 years & 8.2 \\
\hline Henzel et al., 2006 & 84 & FSRT & 11.1 & 56 & 30 & 100 & NA \\
\hline Brell et al., 2006 & 30 & FSRT & 11.3 & 52 & 50 & 93 at 4 years & 6.6 \\
\hline Hamm et al., 2008 & 183 & FSRT & 27.4 & 56 & 36 & 97 at 5 years & 8.2 \\
\hline Litré et al., 2009 & 100 & FSRT & NA & 45 & 33 & 94 at 3 years & 0 \\
\hline Metellus et al., 2010 & 47 & FSRT & 12.6 & 52.9 & 82.8 & 98 at 5 and 96 at 10 years & 2.6 \\
\hline Tanzler E et al., 2010 & $144^{* *}$ & FSRT & NA & 52.7 & 96 & 97 at 5 and 96 at 10 years & 7 \\
\hline
\end{tabular}

CRT, conformal 3-D radiotherapy; FSRT, fractionated stereotactic radiotherapy.

* Series include some patients with intracranial meningiomas.

** 41 patients received CRT. 
results, with a tumor control of $90 \%$ at 5 years, suggest that a dose of $50 \mathrm{~Gy}$ in 30 fractions may achieve a good local tumor control with acceptable toxicity in large skull base meningiomas.

SRS represents an effective and safe alternative treatment option for patients with skull base meningiomas. At doses of 12-16 Gy the reported actuarial 5-year and 10 -year tumor local control rates are in the range of 90$95 \%$ and $80-85 \%$, as shown in some recent large series [46-58]; however, larger tumors are associated with worse long-term local control and increased toxicity $[49,54,55]$. DiBiase et al [49] reported a significant higher 5-year tumor control in patients with meningiomas $<10 \mathrm{ml}$ than those with larger tumors $(92 \%$ vs $68 \%, p=0.038)$. In a large series of 972 patients with meningioma treated with Gamma Knife SRS using a median dose to the tumor margin of $13 \mathrm{~Gy}$ local control was negatively correlated with increasing volume $(\mathrm{p}=$ 0.01 ), and a similar trend was observed with disease-specific survival $(p=0.11)$ [54]. In a retrospective review of 116 patients treated with SRS for meningiomas $>10$ $\mathrm{cm}^{3}$ in volume at a dose of $15 \mathrm{~Gy}$, Bledsoe et al [55] reported a local control of $92 \%$ at 7 years, although complications occurred in $18 \%$ of patients with skull base tumors. Interestingly, Iwai et al [53] using a median marginal dose ranging from 8 to 12 Gy showed a progression-free survival of $93 \%$ and $83 \%$ at 5 and 10 years in 108 patients with skull base meningiomas treated with Gamma Knife SRS; permanent neurological deficits occurred in $6 \%$ of patients. Although the use of radiosurgical doses less than 12 Gy may represent a promising approach in patients with large meningiomas, the reported favourable outcome needs to be confirmed in future studies. Currently, results from published series suggest that FSRT is a better treatment option in such patients based on its proven efficacy and safety.

Hypopituitarism was the most commonly reported late complication. A new pituitary hormone deficit requiring hormone replacement occurred in $19 \%$ of patients. Late neurological toxicity was observed in $7 \%$ of patients and consisted of worsening of pre-existing cranial deficits in 3 patients and mild neurocognitive dysfunction in one patient. A neurological improvement was observed in $19 \%$ of patients; vision remained stable in 46 patients and improved in 7 patients with visual impairment. Since the late effects of radiotherapy in terms of normal tissue damage expressed as radiation optic neuropathy occur usually within 1-5 years of treatment, the low incidence of radiation-induced optic neuropathy and others cranial nerve deficits at a median follow-up of 42 months provide some reassurance about the safety of the present dose and technique for large skull base meningiomas. The present and some other recent series on FSRT [34-45] and conformal RT [15,17] definitely contradict the historical perception of unresponsiveness of meningiomas as well as the considerably concern of high late morbidity following the radiation treatment for benign brain tumors, which was primarily based on old reports where radiation was delivered with orthovoltage machines.

We conclude that FSRT is a high precise and safe treatment for the majority of large skull base meningiomas, with a control of tumor growth at 5 years comparable to that seen following conventional fractionated radiotherapy. For patients with large skull base meningiomas a combination of conservative surgery and postoperative irradiation should always be considered when an attempt to complete resection carries unacceptable risks of neurological deficits. The use of 2-3 $\mathrm{mm}$ margin from GTV to generate PTV with FSRT permits a more localized irradiation compared with conventional radiotherapy. Minimizing the radiation dose to normal brain FSRT may reduce the risk of developing late radiationinduced toxicity; however, the potential benefit in reducing long term treatment complications while maintaining a high efficacy will require longer follow-up of a large cohort of patients.

\section{Acknowledgements}

We are grateful to Mr. Davide Mollo for his excellent technical assistance during the study.

\section{Author details}

'Department of Radiation Oncology, Sant' Andrea Hospital, Università degli Studi di Roma "La Sapienza", Rome, Italy. 'Department of Neurological Sciences, Division of Neurosurgery, Università degli Studi di Napoli Federico II, Naples, Italy. ${ }^{3}$ Department of Neurosurgical Sciences, Division of Neurosurgery, Neuromed Institute, Pozzilli (IS), Italy.

\section{Authors' contributions}

GM conceived of the study, participated in its design and coordination, and drafted the manuscript. LV and VE participated in study design, analysis and interpretation of data, and helped to draft the manuscript. EC and MFO performed the statistical analysis and participated in acquisition and analysis of data. PC, GC and RME critically reviewed/revised the article. All authors read and approved the final manuscript.

\section{Competing interests}

The authors declare that they have no competing interests.

Received: 27 December 2010 Accepted: 12 April 2011

Published: 12 April 2011

\section{References}

1. Sekhar LN, Jannetta PJ: Cerebellopontine angle meningiomas. Microsurgical excision and follow-up results. J Neurosurg 1984, 60:500-5.

2. Mirimanoff RO, Dosoretz DE, Linggood RM, Ojemann RG, Martuza RL: Meningioma: analysis of recurrence and progression following neurosurgical resection. J Neurosurg 1985, 62:18-24.

3. Kallio M, Sankila R, Hakulinen T, Jääskeläinen J: Factors affecting operative and excess long-term mortality in 935 patients with intracranial meningioma. Neurosurgery 1992, 31:2-12.

4. DeMonte F, Smith HK, al-Mefty O: Outcome of aggressive removal of cavernous sinus meningiomas. J Neurosurg 1994, 81:245-51.

5. Cusimano MD, Sekhar LN, Sen CN, et al: The results of surgery for benign tumors of the cavernous sinus. Neurosurgery 1995, 37:1-9. 
6. Couldwell WT, Fukushima T, Giannotta SL, Weiss MH: Petroclival meningiomas: surgical experience in 109 cases. J Neurosurg 1996, 84:20-8.

7. De Jesús O, Sekhar LN, Parikh HK, Wright DC, Wagner DP: Long-term follow-up of patients with meningiomas involving the cavernous sinus: recurrence, progression, and quality of life. Neurosurgery 1996, 39:915-9.

8. Mathiesen T, Lindquist C, Kihlström L, Karlsson B: Recurrence of cranial base meningiomas. Neurosurgery 1996, 39:2-7.

9. O'Sullivan MG, van Loveren HR, Tew JM: The surgical resectability of meningiomas of the cavernous sinus. Neurosurgery 1997, 40:238-44.

10. Stafford SL, Perry A, Suman VJ, et al: Primarily resected meningiomas: outcome and prognostic factors in 581 Mayo Clinic patients, 1978 through 1988. Mayo Clin Proc 1998, 73:936-42.

11. Abdel-Aziz KM, Froelich SC, Dagnew E, et al: Large sphenoid wing meningiomas involving the cavernous sinus: conservative surgical strategies for better functional outcomes. Neurosurgery 2004, 54:1375-83.

12. Shrivastava RK, Sen C, Costantino PD, Della Rocca R: Sphenoorbital meningiomas: surgical limitations and lessons learned in their long-term management. J Neurosurg 2005, 103:491-7.

13. Sindou M, Wydh $E$, Jouanneau $E$, Nebbal M, Lieutaud T: Long-term followup of meningiomas of the cavernous sinus after surgical treatment alone. J Neurosurg 2007, 107:937-44

14. Natarajan SK, Sekhar LN, Schessel D, Morita A: Petroclival meningiomas: multimodality treatment and outcomes at long-term follow-up. Neurosurgery 2007, 60:965-79.

15. Goldsmith BJ, Wara WM, Wilson CB, Larson DA: Postoperative irradiation for subtotally resected meningiomas. A retrospective analysis of 140 patients treated from 1967 to 1990. J Neurosurg 1994, 80:195-201.

16. Nutting C, Brada M, Brazil L, et al: Radiotherapy in the treatment of benign meningioma of the skull base. J Neurosurg 1999, 90:823-7.

17. Mendenhall WM, Morris CG, Amdur RJ, Foote KD, Friedman WA Radiotherapy alone or after subtotal resection for benign skull base meningiomas. Cancer 2003, 98:1473-82.

18. Brada M, Ajithkumar TV, Minniti G: Radiosurgery for pituitary adenomas. Clin Endocrinol (Oxf) 2004, 61:531-43.

19. Minniti G, Traish D, Ashley S, Gonsalves A, Brada M: Fractionated stereotactic conformal radiotherapy for secreting and nonsecreting pituitary adenomas. Clin Endocrinol (Oxf) 2006, 64:542-8.

20. Andrews DW, Suarez O, Goldman HW, et al: Stereotactic radiosurgery and fractionated stereotactic radiotherapy for the treatment of acoustic schwannomas: comparative observations of 125 patients treated at one institution. Int J Radiat Oncol Biol Phys 2001, 50:1265-78.

21. Combs SE, Welzel T, Schulz-Ertner D, Huber PE, Debus J: Differences in clinical results after LINAC-based single-dose radiosurgery versus fractionated stereotactic radiotherapy for patients with vestibula schwannomas. Int J Radiat Oncol Biol Phys 2010, 76:193-200.

22. Minniti G, Saran F, Traish D, et al: Fractionated stereotactic conformal radiotherapy following conservative surgery in the control of craniopharyngiomas. Radiother Oncol 2007, 82:90-5.

23. Minniti G, Esposito V, Amichetti M, Enrici RM: The role of fractionated radiotherapy and radiosurgery in the management of patients with craniopharyngioma. Neurosurg Rev 2009, 32:125-32.

24. Minniti G, Amichetti M, Enrici RM: Radiotherapy and radiosurgery for benign skull base meningiomas. Radiat Oncol 2009, 4:42.

25. Minniti $G$, Valeriani $M$, Clarke $E$, et al: Fractionated stereotactic radiotherapy for skull base tumors: analysis of treatment accuracy using a stereotactic mask fixation system. Radiat Oncol 2010, 5:1.

26. Maire JP, Caudry M, Guérin J, et al: Fractionated radiation therapy in the treatment of intracranial meningiomas: local control, functional efficacy, and tolerance in 91 patients. Int J Radiat Oncol Biol Phys 1995, 33:315-21.

27. Peele KA, Kennerdell JS, Maroon JC, et al: The role of postoperative irradiation in the management of sphenoid wing meningiomas. A preliminary report. Ophthalmology 1996, 103:1761-6.

28. Condra KS, Buatti JM, Mendenhall WM, Friedman WA, Marcus RB, Rhoton AL: Benign meningiomas: primary treatment selection affects survival. Int J Radiat Oncol Biol Phys 1997, 39:427-36.

29. Connell PP, Macdonald RL, Mansur DB, Nicholas MK, Mundt AJ: Tumor size predicts control of benign meningiomas treated with radiotherapy. Neurosurgery 1999, 44:1194-9.

30. Maguire PD, Clough R, Friedman AH, Halperin EC: Fractionated externalbeam radiation therapy for meningiomas of the cavernous sinus. Int $J$ Radiat Oncol Biol Phys 1999, 44:75-9.
31. Vendrely $V$, Maire JP, Darrouzet $V$, et al: Fractionated radiotherapy of intracranial meningiomas: 15 years' experience at the Bordeaux University Hospital Center. Cancer Radiother 1999, 3:311-7.

32. Dufour H, Muracciole $X$, Métellus $P$, Régis J, Chinot $O$, Grisoli F: Long-term tumor control and functional outcome in patients with cavernous sinus meningiomas treated by radiotherapy with or without previous surgery: is there an alternative to aggressive tumor removal? Neurosurgery 2001, 48:285-94.

33. Pourel N, Auque J, Bracard S, et al: Efficacy of external fractionated radiation therapy in the treatment of meningiomas: a 20-year experience. Radiother Oncol 2001, 61:65-70.

34. Debus J, Wuendrich M, Pirzkall A, et al: High efficacy of fractionated stereotactic radiotherapy of large base-of-skull meningiomas: long-term results. J Clin Oncol 2001, 19:3547-53.

35. Jalali R, Loughrey C, Baumert B, et al: High precision focused irradiation in the form of fractionated stereotactic conformal radiotherapy (SCRT) for benign meningiomas predominantly in the skull base location. Clin Oncol (R Coll Radiol) 2002, 14:103-9.

36. Lo SS, Cho KH, Hall WA, et al: Single dose versus fractionated stereotactic radiotherapy for meningiomas. Can J Neurol Sci 2002, 29:240-8.

37. Torres RC, Frighetto L, De Salles AA, et al: Radiosurgery and stereotactic radiotherapy for intracranial meningiomas. Neurosurg Focus 2003, 14:e5.

38. Selch MT, Ahn E, Laskari A, et al: Stereotactic radiotherapy for treatment of cavernous sinus meningiomas. Int J Radiat Oncol Biol Phys 2004, 59:101-11

39. Milker-Zabel S, Zabel A, Schulz-Ertner D, Schlegel W, Wannenmacher M, Debus J: Fractionated stereotactic radiotherapy in patients with benign or atypical intracranial meningioma: long-term experience and prognostic factors. Int J Radiat Oncol Biol Phys 2005, 61:809-16.

40. Brell $M$, Villà $S$, Teixidor $P$, et al: Fractionated stereotactic radiotherapy in the treatment of exclusive cavernous sinus meningioma: functional outcome, local control, and tolerance. Surg Neurol 2006, 65:28-33.

41. Henzel M, Gross MW, Hamm K, et al: Significant tumor volume reduction of meningiomas after stereotactic radiotherapy: results of a prospective multicenter study. Neurosurgery 2006, 59:1188-94.

42. Hamm K, Henzel M, Gross MW, Surber G, Kleinert G, Engenhart-Cabillic R: Radiosurgery/stereotactic radiotherapy in the therapeutical concept for skull base meningiomas. Zentralbl Neurochir 2008, 69:14-21.

43. Litré CF, Colin P, Noudel R, et al: Fractionated stereotactic radiotherapy treatment of cavernous sinus meningiomas: a study of 100 cases. Int J Radiat Oncol Biol Phys 2009, 74:1012-7.

44. Metellus P, Batra S, Karkar S, et al: Fractionated Conformal Radiotherapy in the Management of Cavernous Sinus Meningiomas: Long-Term Functional Outcome and Tumor Control at a Single Institution. Int J Radiat Oncol Biol Phys 2010, 78(3):836-43.

45. Tanzler E, Morris CG, Kirwan JM, Amdur RJ, Mendenhall WM: Outcomes of WHO Grade I Meningiomas Receiving Definitive or Postoperative Radiotherapy. Int J Radiat Oncol Biol Phys 2010.

46. Stafford SL, Pollock BE, Foote RL, et al: Meningioma radiosurgery: tumor control, outcomes, and complications among 190 consecutive patients. Neurosurgery 2001, 49:1029-37.

47. Nicolato A, Foroni R, Alessandrini F, Maluta S, Bricolo A, Gerosa M: The role of Gamma Knife radiosurgery in the management of cavernous sinus meningiomas. Int J Radiat Oncol Biol Phys 2002, 53:992-1000.

48. Lee JY, Niranjan A, Mclnerney J, Kondziolka D, Flickinger JC, Lunsford LD: Stereotactic radiosurgery providing long-term tumor control of cavernous sinus meningiomas. J Neurosurg 2002, 97:65-72.

49. DiBiase SJ, Kwok Y, Yovino S, et al: Factors predicting local tumor control after gamma knife stereotactic radiosurgery for benign intracranial meningiomas. Int J Radiat Oncol Biol Phys 2004, 60:1515-19.

50. Pollock BE, Stafford SL: Results of stereotactic radiosurgery for patients with imaging defined cavernous sinus meningiomas. Int J Radiat Oncol Biol Phys 2005, 62:1427-31.

51. Kollová A, Liscák R, Novotný J, Vladyka V, Simonová G, Janousková L: Gamma Knife surgery for benign meningioma. J Neurosurg 2007, 107:325-36.

52. Hasegawa T, Kida Y, Yoshimoto M, Koike J, lizuka H, Ishii D: Long-term outcomes of Gamma Knife surgery for cavernous sinus meningioma. J Neurosurg 2007, 107:745-51.

53. Iwai $Y$, Yamanaka $\mathrm{K}$, Ikeda H: Gamma Knife radiosurgery for skull base meningioma: long-term results of low-dose treatment. J Neurosurg 2008 109:804-10. 
54. Kondziolka D, Mathieu D, Lunsford LD, et al: Radiosurgery as definitive management of intracranial meningiomas. Neurosurgery 2008, 62:53-8.

55. Bledsoe JM, Link MJ, Stafford SL, Park PJ, Pollock BE: Radiosurgery for large-volume $(>10 \mathrm{~cm} 3)$ benign meningiomas. J Neurosurg 2010, 112:951-6.

56. Flannery $T$ J, Kano H, Lunsford LD et al: Long-term control of petroclival meningiomas through radiosurgery. J Neurosurg 2010, 112:957-64.

57. Nakaya K, Niranjan A, Kondziolka D, et al: Gamma knife radiosurgery for benign tumors with symptoms from brainstem compression. Int I Radiat Oncol Biol Phys 2010, 77:988-95.

58. Zada G, Pagnini PG, Yu C, et al: Long-term Outcomes and Patterns of Tumor Progression After Gamma Knife Radiosurgery for Benign Meningiomas. Neurosurgery 2010, 67:322-9.

doi:10.1186/1748-717X-6-36

Cite this article as: Minniti et al:: Fractionated stereotactic conformal radiotherapy for large benign skull base meningiomas. Radiation Oncology 2011 6:36.

\section{Submit your next manuscript to BioMed Central} and take full advantage of:

- Convenient online submission

- Thorough peer review

- No space constraints or color figure charges

- Immediate publication on acceptance

- Inclusion in PubMed, CAS, Scopus and Google Scholar

- Research which is freely available for redistribution

Submit your manuscript at www.biomedcentral.com/submit 